\title{
REPRODUCING THE INSTITUTIONAL DISCOURSES: A CRITICAL LANGUAGE AWARENESS APPROACH
}

NAHID ZARRINJOOEI ${ }^{1}$

Razi University of Kermanshah, Iran

\begin{abstract}
Since "consciousness is the first step towards emancipation" (Fairclough, 1989, p. 233), and since reproducing the ideological power-bearing discourses and hierarchical relations needs foregrounding the taken-for-granted relations in academic settings, the present study focuses on the different discourses and interactions of supervisors, advisors, external and internal examiners, and the audience with the M.A. defending students while urging on various orders of discourse with change. The present paper is a qualitative ethnography-based approach and sees into various commonsensical power-bearing verbal and nonverbal discourses. The specific methods of this work are a long-term observation accompanied by a detailed contextual analysis of five recorded viva sessions in two universities in the west of Iran. The findings of this study, power in discourse and power above discourse, helped in answering how orders of discourse are naturally produced in academic settings generally, and in viva voce settings specifically. Finally, this study concedes that both students and members of the elite groups_professors_comprehend and produce power-bearing discourses without even a minor change, so that the traditionally held and commonsensical ideologies leading to powerful discourses appeared quite legitimate. Compliances resulted in reinforcing commonsensical assumptions in the academic settings. Resistance or social struggle, as the alternative reaction, is suggested at the end of this work which could lead to reforms in academic and educational systems in favor of emancipation. Similar studies can be done in classrooms and the same contexts where there seems to be unequal hierarchical relations for the purpose of bringing about social struggle. This study has implications for higher education specifically, and for education in general.
\end{abstract}

Keywords: Higher education, critical language awareness, viva voce, reproduction

\section{Introduction}

Critical Discourse Analysis (henceforth CDA) is a branch of Discourse Analysis which objects the existing commonsensical relations of power in favor of the marginalized. This is rightly put by Van Dijk (1998) who stated that CDA is a kind of tool that first and foremost probes the way power abuse, dominance, and manipulation are exerted, reproduced and accepted or maybe resisted in the social and institutional contexts. He stipulates that with such endeavors, discourse analysts get critical to understand, analyze and ultimately to question and reject social inequality in various contexts. In this section, Critical Discourse Analysis is introduced as an analytical tool through which analysts can get into the commonsensical discourses for finding any power asymmetrical relations.

CDA, as a very novel approach in the interactive settings like education, has some useful tenets, also manifested in this work. These are inequality, power relations, ideology, dominance, hierarchical orders, and so on. All these key theories are very well fitted in Fairclough's (1989) three stages of CDA. All Fairclough's three stages of CDA are studied the present study. These stages have to do with verbal and nonverbal discourses, invisible ideological assumptions, and power asymmetry abound among the collected codes of this study. He stresses on language use, rather than language usage. He stipulates that

\footnotetext{
1 Department of English Language and Literature, Razi University, Iran.
}

Email: zarrinjooei@aol.com 
discourse cannot be taken from its root, or let's say its context. To clarify this point, I can refer to the effects various orders of discourse can have upon the minds of others whether through coercion or persuasion. Fairclough's (1989) model of critical discourse analysis includes three interrelated processes of analysis, closely connected to three interrelated aspects of discourse. These aspects are the text, production and understanding processes, and the macro social conditions governing them. Fairclough regards a different kind of analysis for each of these aspects of discourse. The first one is called text analysis or simply the description and transcription processes, the second one is processing analysis or interpretation of interactions. The last one is called social analysis or let us call it the explanation stage which necessitates explaining the already existing social structures.

A key concept in re-producing the discourses without change is the matter of transferring old ideologies, backgrounded in the minds of all members of a given society. This has been observed in Van Dijk's (2008) words stating that "remembering our personal experiences as well as remembering what we read in the press, or what we told someone, thus consists in the search for and activation of "old" mental models" (p. 62). Activating old mental models without change leads to re-producing the same old discourses. The representation of old mental models can be re-shaped in a new way by foregrounding them. Interestingly, Van Dijk's (2008) discussion of memory is in line with Fairclough's (1989) discussion of $M R$, or member resources. He also believed that MR influences on the society, while at the same time determining by it. Likewise, Van Dijk (2008) referred to the social knowledge and this implies somehow the same thing that Fairclough (1989) presented as holding images of the society with oneself. Fairclough (1995) stated that "Discourse is use of language seen as a form of social practice, and discourse analysis is analysis of how texts work within socio-cultural practice" (p. 7). By this, he asserts that we cannot separate discourse from its social and cultural roots. Both of them also pointed to the schemata activation for getting help from the past MR or memories. Text, interaction, and context are the other names for Fairclough's (1989) three stages of CDA.

"Critical Discourse Analysis is an approach, a way of looking at texts, not a rigorously systematic method of analysis" (Huckin, 2000, p. 12). Huckin (2000) also adds that the task of an analyst is to confirm, explain, and communicate the existing relations of power in a detailed manner to others. So, the task of systematically analyzing the texts for exploring the social events and relations is on the burden of a critical discourse analyst who is keen enough to find and foreground unequal conditions. "One of the benefits of CDA is its ability to bring together social and linguistic analyses of discourse, thus integrating analysis at the macro level of social structure with analysis at the micro level of social action" (Henderson, 2005 , p. 5). CDA relies on the triangulation of discourse, ideology, and power, each of which are closely interrelated and reinforced by each other.

For the most part, Critical Discourse Studies (CDS), tying to a branch of critical research, came into existence from the Frankfort and neo-marxian tradition (Marx, Gramsci, Althusser), CDA (Fairclough, Wodak, Van Dijk), Faucault and some other branches. McKenna (2004) asserts that CDS's main concerns were discourse and social structures. For CDS, liberty and justice mattered a lot. However, Critical Discourse Analysis, as a new branch to Discourse Analysis emerged in the late 1980s. Its new dimensions were power, inequality, ideology, and hegemony in verbal and nonverbal discourses.

CDA theories and strategies assist in revealing some culture sharing ideologies which had been traditionally kept and transferred to the others. An example of this is the interactions in a viva voce where there are some hierarchical orders and transferring ideologies occurs there very often. In line with this and by transferring some power asymmetrical ideologies to other academic contexts, defending students have to tolerate rather than resist some interactions. As "processes of a thesis are often a source of great anxiety for many students in higher education," (Sachs, 2002, p. 99) these asymmetrical relations add to their anxiety. Hence, the present work is a pioneering one with regard to studying interactions in the viva voce. This study is significant in some ways. Firstly, it is a novel study for making use of critical discourse analysis as a new approach for investigating what is going on in viva contexts. No study ever resorted to critical discourse analysis to unpack the interactions existing in the viva settings. The other thing which made this study significant is that it is an emancipatory study in favor of the marginalized students. It tries to give voice to the voiceless. The voiceless are those who even do not regard rights of voicing for themselves! 
As Wareing $(1999$, p.10) rightly mentioned that "power is a complex and abstract concept, and an infinitely important influence on our lives," it can be noticed that it seems somehow vague upon the first look, because it is a subjective term and no clear-cut definition can be ascribed to it. However power is everywhere, for it comes from the society and society is not limited to a specific boundary (Ritchie, Rigano, \& Lowry, 2000). Different scholars define it differently, but the main concept is one for all. For example, Jones \& Stilwell Peccei (1999) defined it as a kind of force "to persuade people to act voluntarily in the way you want" (p. 38); however this definition is very much similar to what Fairclough (1989) stated about it. He stated that it is the exerting of a kind of hidden force "through the manufacture of consent to or at least acquiescence towards it" (p. 4). This is the link of power to ideology, if we pay attention to these scholars' definitions. To secure this kind of persuasive power, it is relevant to encourage people that what you want them to do is exactly what they want. It means that if one wants to exert power, it is important to enter their minds, influence them, and make sure that what is asked them is in line with their goals and purposes. Also, there is a view of hegemony that discusses a kind of power which is exerted through alliances and integrating people, or much the same as Fairclough's (1989) notion of manufacturing consent (Thornton \& Reynolds, 2006).

Equating their actions and words with goals of the dominated is a strategy often seen in the data of this study when a member of the elite group repeatedly asserts that what is asked the defending student to do is in favor of them to improve their study. Van Dijk (1996) stated that:

Social power is defined in terms of the control exercised by one group or organization (or its members) over the actions and/or the minds of (the members of) another group, thus limiting the freedom of action of the others, or influencing their knowledge, attitudes or ideologies [p. 84].

He also stipulated that this power makes 'centers of power' or 'elite groups.' This term is borrowed from him in the present study to refer to those whose knowledge creates superiority over the others lacking it or having a lesser degree of it. This group includes professors, or external and internal examiners, advisors, and supervisors in the present study. CDA calls the attention of all to the social context of the viva voce in order to break down the taken-for-granted relations and assumptions. Also, it would be appropriate to think of changing the term 'defense' to a better alternative, because the term 'defense' implies some hidden meanings of existing someone to attack, and this is troublesome in educational settings where there should be close and caring relations.

The objective of this study is to augment the awareness of academicians and students by justifying that variations in discourse are also possible, not to think that there is just one to state a discourse in a specific session. The usefulness of this study is that this study aims to make trouble using social struggle strategies. It points to the role of awareness in any educational or academic setting. Raising someone's awareness can be a more potent strategy than forcing her to do something. "Education is seen as a major area for the reproduction of social relations, including representation and identity formation, but also for possibilities of change" (Blommaert \& Bulcaen, 2000, p. 451), so some scholars insist on rethinking power relations in the social or institutional contexts (Smith, 2006 \& Koutsantoni, 2006). They think that by rethinking about the existing power relations equality is achieved in favor of the dominated. So, awareness is accompanied by struggle and resistance. When resisting the hegemonic status quo, the same orders of discourse are not re-produced. So, re-producing occurs in new emancipatory ways. If relations in the viva settings get symmetrical, the educational and academic contexts will surely get influenced by the change.

The literature on M.A. or Ph.D. viva sessions lacks this kind of analysis on their discourses, something that the present study dealt with. It gets connected to the body of literature by critically analyzing the viva voce sessions, something which is studied for the first time. There are some studies on viva contexts, but they do not tackle with the issue from the perspective of CDA. So, the findings of this study add a new dimension to the literature on the viva interactions. "Despite the fact that universities have been assessing doctoral and master's theses for many years, there has been little research done on the processes involved in that assessment" (Tinkler \& Jackson, 2000, cited in Mullins \& Kiley, 2002). 


\section{Methodology}

The data of this qualitative and ethnography-based study were recorded using a handy camera in 5 viva sessions and then they were transcribed carefully for a textual analysis. As we know, qualitative data are forms of information collected in nonnumeric ways. In this study, Qualitative Data Analysis (QDA) was the range of processes and procedures whereby I shifted from the collected data towards some forms of explanation, understanding and interpretation of the people's interactions and situations. Hence, QDA seemed to be based on an interpretative philosophy. The most common forms of qualitative data were what people -with their feelings and experiences- have said or done in viva sessions. It had to examine the meaningful content of the data. So, the textual analysis was a way to organize information about how students and educators made sense of the interactions and experienced the world, and specifically the viva sessions. This data-gathering process analyzed the emerging features and interactions on the text. The strategy of inquiry of the present work was ethnography by which I got involved in academic cultures and settings for discovering culture sharing attitudes and ideologies. It was also a methodology for understanding how members of the elite group and the students made sense of whom they were ideologically and of how they fitted into the academic world in which they lived. The textual analysis was the main method through which the data were collected and organized. It was also exploratory so that by passing the time more and more features were emerged and explored and it had much to do with intuition, thinking, classification, and coding. The interpretive textual analysis included semiotics, rhetorical analysis, and more importantly ideological analysis, among many others. These types of analysis sought to get beneath the surface (denotative) meanings and examine more implicit (connotative) social meanings. I used some techniques for the textual analysis of the interactions in viva sessions, among which were high frequency words, collocations, and the immediate linguistic environment of a specific word.

As advocacy/participatory knowledge claims have "political, empowerment issue-oriented, collaborative, change-oriented positions" (Creswell, 2002, p. 6), they call for change at the end, and question the existing asymmetrical structures. Having this theoretical framework for the present study, it is hoped that naturalized ideas leading to marginalization of some students are all resolved by increasing consciousness of both students and professors.

\section{Results}

After codifying the interactions, two categories of surface features of viva sessions and higher (hegemonic) features were emerged which are drawn below. According to Fairclough (1989), there are three stages of critical discourse analysis: Description, Interpretation, and Explanation. In description, the analyst explores micro features of discourse, like passive vs. active sentences, tag questions, diction, nominalization, positive vs. negative sentences, modes of discourse (declarative, grammatical questions, imperatives, and nonverbal), modality, pronouns, turn taking system, etc. In interpretation, the analyst is concerned with the interaction of texts from production to processes of understanding_ viz., cognitive processes are involved. Finally, in the explanation stage, the analyst deals with the link between interpretations and macro social contexts. Building on the model of Fairclough (1989), the data were transcribed, analyzed, and interpreted, having in mind the triangulation of discourse, ideology, and power. Figure 1 demonstrates this model in order to fully understand the surface layers of Critical Discourse Analysis in the present work. This study shows the way power is enacted, that is, through the invisible link to ideology, and by means of verbal and nonverbal discourses. By critically analyzing the data, some themes were explored which were in line with maxims of CDA, especially ideology and power relations manifest in the institutional orders of discourse.

This work has a voluminous corpus, some part of which is shown here. All the two categories are randomly exemplified below. 


\section{1 interruptions}

Examiner: "Those which have two numbers, then... (decreasing the tone)."

The student: "I see, you mean if... (seeking for clarifications)."

Examiner interrupted: "Hey look, you should have told that."

\subsection{Informal language and humor}

Advisor: "The students write some stuff so simply, all in vain and spurious. Ha-ha. The fact is that it is just for filling the forms! But THIS (referring to the student) has known this."

Advisor (referring to the student): You pinned the blame on me? Huh? Ha-ha-ha."

Examiner (looking humorously): "You are conversant, versant! Ha-ha-ha..."

\subsection{Ignoring the defending students}

Examiner: "As a reader, I have always had this question. Why ...?"

Supervisor: "Dr. if you let me, I will answer. Look ..."

Advisor: "I did not get what that automatic mean!"

Supervisor: "Well ..."

Examiner: "But, the linguistic issues..."

Examiner: "I saw Dr. X's presence everywhere in this thesis, which has turned it to a good one, and it's his noble disposition and true-heartedness which has influenced you not to be bias."

\subsection{Power asymmetry and knowledge management}

Examiner: "In the first page, the translation of systemic-functional theory is really problematic by itself. You should change it totally to Persian."

Audience: "Sorry, but we see that in all translations, they write 'systemi-naghshi.' System is used a lot in Persian."

Examiner: "They have made a big mistake. It's not a good choice, anyway."

Audience: "Dr. X, this form is still used by the Persian Language and Literature Academy. I don't think it's wrong"

Examiner: "l'll talk about it later."

Examiner (totally changes the topic): "Well, her thesis is mostly statisticallyoriented."

Examiner: "Regarding the year and page number, you'd better revise them; Note that because it is a very good work, it'll be really better not to have these minor problems." 
Examiner: "Well, on page 8, for this good work it seems that you should explain more concepts, not just two. You have limited the key concepts in just two, while if you consider in Halliday's theory there are many concepts to talk about."

\subsection{Ceremonial aspects}

Advisor: "I ask permission of all dear professors, you have twenty minutes to present. Please start your presentation and after that, dear examiners do us favor..."

Student: "Seeking permission of all my dear and honorable professors and the audience, I start my presentation under the title ..."

Examiner: "Do you permit, Dr.?

Advisor: "My pleasure! I'm at your service."

Examiner: "With all your permission Dr. Well Ms. X, thank you, more power on your elbow. I have two assessments."

\subsection{Personal beliefs and focus on form}

Examiner: "it seems that you must explain more concepts."

Examiner: "I feel your key words are more than two, and I feel the part 2.3.5 is redundant."

Examiner: "My suggestion is that it should have a little difference."

Examiner: "there are some parts to be revised, and they are formal problems. I have neither expertise nor capability to comment on content. However, I have checked some forms which I tell you."

Examiner: "You have written an extra 'to' right there. I have checked some trivial things too. Don't say they are too strict!"

Examiner: "Ms. $X$, answer in a short time, if the questions were answerable, not just the professors say all the things, and finally finish it; I mean it should have the form of a defence session.

\section{Discussion}

The aim of this study was to increase the awareness of some features of academic settings explored in the data, and to avoid further marginalization of those with low power, because "consciousness is the first step towards emancipation" (Fairclough,1989, p. 233). In order to decrease the chance of further marginalization, it is really important to be conscious of discourse types which bring discriminations with themselves. Likewise, it is important to re-produce meanings with change. It would be really better to change the viva sessions to communicative and interactive encounters in which everyone even the defending students have the right to ask questions and to manage themselves and the settings.

"Lack of power is also measured by its lack of active or controlled access to discourse" (Van Dijk, 1993). If we recognize that we do not have access to a specific order of discourse while the other side has this right and access, then we can understand that we are powerless. Recski (2005) discussed Ph.D. viva sessions and disclosed some features and conditions while stipulating that for an outsider visiting a viva 
session it may seem like a 'battle for power.' Van Dijke (2003) asserted that power leads to stereotyping and discrimination, while adding that power relations exist in all the settings in which people interact. So, we may conclude that interactional contexts result in reinforcing stereotypes, and specifically discriminations. If so, the role of awareness is vital, because without awareness the powerful exert a lot of power and inequalities are spread out. Power abuse may seem 'jointly produced' and it is not to think of power as 'unilaterally imposed on others.' The reason is that power takes the form of power only and only when accepted as natural from the other sides (Van Dijk, 1993). Power holders need others in order to transfer their powers. The contention is that there should be a counter-power if one wants to avoid repercussions of power. It should be noted that power is exerted only when the other side accept it. This point must be kept in mind if we want to support the agenda for changing the traditional conventions and structures. This is somehow supported by Lee \& Tiedens's (2001) study which has a very interesting discussion on the features of power holders. This study shows that power holders actually need others. So, it is up to the dominated whether to accept or to reject inequalities. This study argued that power holders have independent self construals which make them separated from others and interdependent relational structures which put them in a network of relations and connections, while co-occurring. These power holders are socially embedded and interdependent on others for having power in the absence of others is nonsense.

Getting familiar and familiarizing everyone or let us say foregrounding the academic interactions is the best solution for changing the traditionally-held beliefs in favor of caring relations in education, especially higher education. So, social struggle is the aim of the present work achieved by foregrounding the status quo.

5. CONCLUSIONSContrary to the discussions on the power exerted by the elite groups for having a special knowledge and expertise, Carter (2008) regarded the oral exams as a 'dialogue between equals' (p. 371). If the interaction of the defending students and professors is a dialogue between equals, then elite power seems vague.

As Winograd (2002) discussed, power and resistance are situational and shifting and not fixed. By seeking assistance from this study, we can ensure that a student who complied with different orders of discourse can change her stance and use counter-power strategies. Another study suggested that power and counter-power co-exist in pedagogy and curriculum and they work in a dual process of interacting (Benesch, 1999). We can come to the understanding that it may be a false belief to think of power merely as a means by which one group exercise it over the others. It means power is negotiated in a continuum ranging from fully complying and accepting to fully resisting.

\section{Acknowledgements}

The author wishes to thank all those professors and M.A. students who let us videotape their oral exams. No doubt, doing this work was impossible without their help and co-operation.

\section{References}

Benesch, S. (1999). Rights analysis: studying power relations in an academic setting. English for Specific Purposes, 18(4), 313-327.

Blommaert, J. \& Bulcaen, C. (2000). Critical discourse analysis. Annual Reviews. Anthropology, 29, 447-466.

Carter, S. (2008). Examining the doctoral thesis: A discussion. Innovations in Education and Teaching International, 45(4), 365-374.

Creswell, J.W. (2002). Research Design: Qualitative, Quantitative, and Mixed Methods Approaches. Thousand Oaks, London, New Delhi: Sage Publications.

Fairclough, N. (1989). Language and Power. London and New York: Longman.

Fairclough, N. (1995). Critical Discourse Analysis: The Critical Study of Language. London \& New York: Longman. 
Huckin, T. (2002). Critical discourse analysis and the discourse of condescension. Discourse Studies, Ch. 7, 1- 27.

Jones, J. \& Stilwell Peccei, J. (1999). Language and Politics. In Thomas, L., et al. (Eds.), Language, Society, and power: An Introduction (2nd Ed., pp. 35-54). London and New York: Routledge.

Koutsantoni. D. (2006). Rhetorical strategies in engineering research articles and research theses: Advanced academic literacy and relations of power. Journal of English for Academic Purposes, 5, 19-36.

Lee, F. \& Tiedens, L.Z. (2001). Is it lonely at the top?: The independence and interdependence of power holders. Research in Organizational Behavior, 23, 43-91.

McKenna, B. (2004). Critical discourse studies: Where to from here? Critical Discourse Studies, 1, 9-39.

Mullins, G. \& Kiley, M. (2002). 'It's a PhD, not a Noble Prize': how experienced examiners assess research theses. Studies in Higher Education, 27(4), 369-386.

Recski, L. (2005). Interpersonal engagement in academic spoken discourse: a functional account of dissertation defenses. English for Specific Purposes, 24, 5-23.

Ritchie, S.M., Rigano, D.L. \& Lowry, R.J. (2000). Shifting power relations in "the getting of wisdom". Teaching and Teacher Education, 16, 165-177.

Sachs, J. (2002). A path model for students' attitude to writing a thesis. Scadinavian Journal of Educational Research, 46(1), 99-106.

Smith, K.E. (2006). Problematising power relations in 'elite' interviews. Geoforum, 37, 643-653.

Thornton, S. \& Reynolds, N. (2006). Analyzing classroom interactions using critical discourse analysis. Psychology of Mathematics Education, 5, 273-280.

Van Dijk, T. (1993). Principles of critical discourse analysis. Discourse \& Society, 4(2), 249-283.

Van Dijk, T. (1996). Discourse, Power, and Access. In Caldas-Coulthard, C. R. \& Coulthard, M. (Eds.), Texts and Practices: Readings in Critical Discourse Analysis (pp. 84-104). London and New York: Routledge.

Van Dijk, T. (1998). Critical discourse analysis. To appear in Deborah Tannen, Deborah Schiffrin \& Heidi Hamilton (Eds.), Handbook of Discourse Analysis. Second draft. http://www.hum.uva.nl/ teun/cda.htm

Van Dijk, T. (2008). Discourse and Context: A Sociocognitive Approach. Cambridge, New York, Melbourne, Madrid, Cape Town, Singapore, São Paulo: Cambridge University Press.

Wareing, S. (1999). What Is Language and What Does It Do? In Thomas, L., et al. (Eds.). Language, Society, and Power: An Introduction (2nd Ed., pp. 1-16). London and New York: Routledge.

Winograd, K. (2002). The negotiative dimension of teaching: teachers sharing power with the less powerful. Teaching and Teacher Education, 18, 343-362.

Fecha de recepción / Received: 05/03/2016

Fecha de aceptación / Accepted: 22/05/2016 